\title{
Burden, reward, and coping of adult offspring of patients with depression and bipolar disorder
}

\author{
Rita Bauer ${ }^{1,2^{*}}$, Hermann Spiess $\left.\right|^{3}$ and Marina J Helmbrecht ${ }^{4}$
}

\begin{abstract}
Background: In previous years, research has focused on the situation of psychiatric patients' minor children. The aims of this qualitative study were to describe the experience of adult children of depressed and bipolar patients, including positive and negative factors as well as coping mechanisms, and to investigate possible predictors of burden in order to identify children in need of professional support.

Methods: A total of 30 adult children were interviewed using a semi-structured interview. In addition, all children completed the Freiburg Questionnaire of Coping with Disease (Freiburger Fragebogen zur Krankheitsverarbeitung, FKV). Regression analysis indicated the most relevant predictors of burden.

Results: All (100\%) of the children reported emotional burden due to the illness of their parent, $90 \%$ suffered from impaired family life, and 77\% experienced burden due to the parent's symptoms. Reward (positive experience) was reported regarding the intensification of the parent-child relationship. Linear regression analysis shows predictors for highly burdened children as well as for children who are more prone to maladaptive ways of coping. Higher burden was significantly associated with the child's age, severity of illness of the parent, and specific diagnosis.

Conclusions: Although some positive aspects of parental affective disorder exist, this study underlines that children primarily suffer from their parent's disorder and that this burden does not stop in adulthood. Providing professional support to adult as well as to minor children of affected individuals should become standard of care in clinical settings.
\end{abstract}

Keywords: Bipolar disorder; Depression; Caregiver; Burden; Reward of caregiving

\section{Background}

Typically, the term 'a sample of caregivers' refers to parents and partners but rarely to children. In studies exploring caregiver burden, children of psychiatric patients tend to comprise a small part of a heterogeneous subject group (e.g., Cleary et al. 2005; Reinares et al. 2006; Adewuya et al. 2011). Chronic psychiatric disorders, such as bipolar and depressive disorder, often end in serious problems like loss of job, poverty, or decrease of social functioning - even in times when the patient is symptom-free (Bauer et al. 2012a; Coryell et al. 1993). Of all relatives, children are the only ones being completely dependent on the psychiatric patient. There is no doubt that minor

\footnotetext{
* Correspondence: Rita.Bauer@uniklinikum-dresden.de

'Department of Psychiatry and Psychotherapy, University Hospital Carl Gustav Carus, Technical University Dresden, Fetscherstr. 74, 01307 Dresden, Germany

${ }^{2}$ Department of Psychiatry and Psychotherapy, University of Regensburg, Universitätsstraße 84, 93053 Regensburg, Germany

Full list of author information is available at the end of the article
}

offspring of mentally ill parents experience a high level of burden (Krautgartner et al. 2007; Stelling et al. 2008) and are at a high risk for developing social, emotional, and behavioral disorders (Duffy et al. 2014; Maoz et al. 2014). Especially if they are the only caregivers of the patient, children suffer most from those psychosocial difficulties. It is known that caregivers of affected individuals show high levels of psychopathology and burden (Adewuya et al. 2011) and that those who are unable to cope effectively report the most burdensome experiences (Chakrabarti and Gill 2002). Moreover, caregiver burden continues in times of remission (Reinares et al. 2006) and is associated with patient dysfunction, duration of illness (Chakrabarti et al. 1992; Mitsonis et al. 2012), and symptom severity (Hjäthag et al. 2010).

To date, no study has been conducted that describes the burden adult children experience as a consequence of parental psychiatric disorder.

\section{实}

(c) 2015 Bauer et al.; licensee Springer. This is an Open Access article distributed under the terms of the Creative Commons Attribution License (http://creativecommons.org/licenses/by/4.0), which permits unrestricted use, distribution, and reproduction in any medium, provided the original work is properly credited. 
Furthermore, as far as to the last decade, the situation of caregivers was explored only as burdensome. Paradigm shift from one-sided analysis of caregiver burden to a more differentiated view of the situation of the caregivers is new (Bauer et al. 2012b). Little attention has been paid to the positive aspects and rewards of caregiving (Schwartz and Gidron 2002; Veltman et al. 2002). This one-sided focus of research does not justify the complexity of the numerous changes that result from caring for someone with a mental illness. The few studies of rewards of caregiving constrain a multitude of profit, most appreciation by the patient and others for the caregiving and satisfaction about providing care and an increase of cohesion and closer relationships with the patient and within the family (Bauer et al. 2012b, 2013; Schwartz and Gidron 2002). Reflecting reward of caregiving one's parent and developing individual coping strategies in handling mental disorder of a family member are often closely connected.

Therefore, the aim of this study was to investigate the situation - burden, reward, and ways of coping - of adult offspring of parents with bipolar disorder (OBD) and of adult offspring of parents with depressive disorder (ODD).

\section{Methods}

\section{Subjects}

Patients with either bipolar disorder or depressive disorder (ICD-10 F31.x and F32.x/F33.x) and who had at least one adult child were recruited consecutively 6 months along to participate in the study during their psychiatric hospitalization. Patients and adult children were informed about the study and were offered to participate voluntarily. The study protocol was approved by the ethics committee of the Medical Faculty of the University of Regensburg, and all participants gave their written informed consent to participate. One hundred twenty-four patients were contacted: 6 did not want any contact with our interviewer, 40 stated not to have children, 15 patients only had minor children, and 63 had adult children who could be included in our study. Of these 63 patients who were asked for permission to contact their adult child/children, 33 (52.4\%) agreed and gave their written informed consent. Of the 33 children contacted, 30 (90.9\%) agreed to participate in the study and 3 (9.1\%) did not. Those 30 children came from 30 separate patients. The socio-cultural-economic background of the participants (patients as well as interviewed children) is comparable. There are no significant group comparisons in the characteristics for the children (ODD vs. OBD). The tested characteristics are gender, age, level of graduation, employment, marital status, common household with the patient, number of persons in the household, monthly take-home amount, hours of contact with the patient per week, distance between place of residence and clinic, legal guardianship of the patient, and taking part of a psychoeducational caregiver group. The only significant difference in the group comparisons in the characteristics for the patients (ODD vs. OBD) was in the psychosocial functioning (GAF). The OBD group had a significantly lower psychosocial functioning at discharge than the ODD $[Z(N=26)=-2.05 ; P<.05]$. The tested characteristics are gender, age, level of graduation, employment, duration of illness, psychotherapy before admission, history of suicide attempts, clinical global impression (CGI part 1) at admission, global assessment of functioning at admission and discharge (CGI), legal guardianship, mentally ill, firstdegree family members, comprehension of caregivers in patient's treatment, and situation of living of the patient after discharge.

\section{Instruments}

Clinical records of the patients were complemented with socio-demographic variables assessed through a small questionnaire answered by all patients.

The assessment of the adult children involved a selfgenerated interview using a semi-structured schedule assessing both objective and subjective burden of care. Furthermore, the schedule included one question regarding reward: 'Did you experience any positive changes in your life due to your parent's illness?' All interviews were done by one rater (psychologist), trained by experienced psychologists in different workshops in psychological interviewing. The interviews were audio-taped and transcribed. In addition, the Freiburg Questionnaire of Coping with Disease (Freiburger Fragebogen zur Krankheitsverarbeitung, FKV, Muthny 1989) was used to assess illness adjustment. Using this questionnaire, five coping strategies can be distinguished: (i) 'Depressive coping' (i.e., 'accusing himself'), (ii) 'Active problem-orientated coping' (i.e., 'seeking information about illness and therapy'), (iii) 'Distraction and building self-esteem' (i.e., 'showing feelings of one's own to other people'), (iv) 'Religiousness and searching for meaning' (i.e., 'trying to find a sense for the illness'), and (v) 'Trivialization and wishful thinking' (i.e., 'downplay the importance and relevance of the illness'). Furthermore, socio-demographic data of all children were collected.

\section{Analyses}

The interview transcripts were analyzed using summarizing qualitative content analysis (Mayring 2000; Silverman 2001). An inter-rater reliability of $\kappa=.93$ was obtained. For further evaluation, a sum score, based on the number of negative/positive results reported, was calculated, which assessed all items equally.

To compare this sum score and to assess potential statistical differences between the offspring of patients with bipolar disorder (OBD) and the offspring of patients 
with depressive disorder (ODD), $t$-tests as well as Fisher's exact tests were used.

Linear regression analyses built by backward elimination and model refinement on the basis of the adjusted $R^{2}$ were carried out to identify the variables which explained best the variance of burden and coping strategies. All clinical variables (inclusive diagnosis) regardless of the group differences were included as independent variables. The three dependent variables that were used were the sum score of reported burden, and the coping strategies 'Depressive coping' and 'Trivialization and wishful thinking, which were seen as maladaptive coping strategies.

Statistical significance was set at $\alpha \leq .05$. Statistical analysis was performed with the Statistical Package for Social Sciences (SPSS) software, version 16.0.

\section{Results}

\section{Sample description}

The patient sample consisted of 19 female (63.3\%) and 11 male (36.7\%) patients of whom $9(30 \%)$ were 49 years or younger, $10(33.3 \%)$ were between 50 and 59 years old, and $11(36.7 \%)$ were older than 60 years. Fifteen (15) patients had bipolar disorder, and 15 had depressive disorder. The children sample consisted of 20 (66.7\%) female and 10 male (33.3\%) persons between 18 and 46 years old. Demographics for patients and their children are reported in Table 1.

Duration of the interviews was 13 to 71 min with an average of $28.6 \mathrm{~min}$.

\section{Burden experienced due to the parent's disorder}

The children's statements were summarized into 38 global statements and assigned to eight categories of burden: emotional burden (reported by 100\%), burden due to impaired family life (90\%), burden due to the patient's symptoms $(76.7 \%)$, burden due to dissatisfaction with the patient's therapy/professional staff $(73.3 \%)$, burden due to impaired free-time activities (63.3\%), burden due to impaired functioning in school/job (46.7\%), burden due to own health problems (43.3\%), and burden due to problems in the child's relationship/own family (30.0\%). Categories and statements are more precisely listed in Table 2.

There was no significant difference between the sum score of the OBD and the ODD $[t(N=30)=-1.55$; $p=.97$ ]. However, OBD reported significantly more burden due to impaired functioning in school/job $(66.7 \% \mathrm{vs}$. $26.7 \% ; p=.03$ ), whereas ODD reported significantly more burden due to dissatisfaction with the patient's therapy/ professional staff ( $93.3 \%$ vs. $53.3 \% ; p=.02)$.

\section{Factors predicting the experience of burden}

Adult children reported more burdensome aspects when they were either younger than 11 or older than 20 years old at the onset of their parent's disorder $(\beta=-.513$; $p=.00$ ), when severity of parent's illness was high at date of discharge $(\beta=.337 ; p=.04)$, and when the parent was diagnosed with bipolar disorder vs. depression $(\beta=338 ; p=.04)$. The variables explained $47 \%$ of the total variance $\left(R^{2}=0.468 ; n=26\right)$.

\section{Reward experienced due to the parent's disorder}

Despite the fact that the schedule included only one question regarding reward, six categories regarding reward could be found: reward due to feeling closer to the healthy parent (reported by $46.7 \%$; sum score OBD:ODD $=10: 4$ ), reward due to the family growing closer as a whole $(23.3 \% ; 3: 4)$, reward due to feeling closer to the ill parent $(23.3 \% ; 2: 5)$, reward due to the development of personality traits considered positive $(13.3 \% ; 2: 2)$, reward due to feeling closer to the sibling(s) $(6.7 \% ; 0: 2)$, and reward due to feeling closer to their partner/husband/wife (3.3\%; 1:0).

There was no significant difference between the sum score of the OBB and the ODD [ $t(N=30)=.00 ; p=.32]$, although OBD reported significantly more reward due to feeling closer to the healthy parent $(66.7 \%$ vs. $26.7 \%$; $p=.03)$.

\section{Ways of coping}

OBD and ODD of this sample used a wide range of coping strategies, none of which was predominant. Nevertheless, OBD used significantly more 'Depressive coping' $(p=.01)$ and also more 'Distraction and building self-esteem' $(p=.05)$ than ODD.

\section{Factors predicting maladaptive coping in adult children}

Five factors were found to predict 'Depressive coping': ill parent being single $(\beta=-.592 ; p=.06)$, adult child being of younger age $(\beta=-.485 ; p=.01)$, adult child reporting more burdensome aspects $(\beta=-.289 ; p=.05)$, adult child being in a cohabitating relationship $(\beta=-.455 ; p=.01)$, and parent being diagnosed with bipolar disorder $(\beta=-.469$; $p=.00)$. The variables explained $59 \%$ of the total variance $\left(R^{2}=0.586 ; n=30\right)$.

Six factors were found to predict 'Trivialization and wishful thinking' best: parent (i.e., patient) not being under legal tutelage $(\beta=-.768 ; p=.00)$, parent being single $(\beta=-.302$; $p=.04)$, parent having attempted suicide $(\beta=.299 ; p=.04)$, parent being diagnosed with bipolar disorder $(\beta=.323$; $p=.04$ ), adult child being 10 years or younger at the onset of the parental illness $(\beta=.423 ; p=.00)$, and adult child being the parent's legal custodian $(\beta=.558 ; p=.00)$. The variables explained $71 \%$ of the total variance $\left(R^{2}=0.709 ; n=30\right)$.

\section{Discussion}

Specific burden of children as caregivers

Predominately, adult children of parents suffering from bipolar or depressive disorder show high levels of burden 
Table 1 Characteristics of the children and patient sample

\begin{tabular}{|c|c|c|c|c|c|c|c|}
\hline \multicolumn{2}{|l|}{ Characteristics of the adult children sample } & \multicolumn{2}{|c|}{ Total $[N=30]$} & \multicolumn{2}{|c|}{ OBD $[n=15]$} & \multicolumn{2}{|c|}{ ODD $[n=15]$} \\
\hline \multirow[t]{2}{*}{ Gender } & Female & 20 & 66.7 & 10 & 66.7 & 10 & 66.7 \\
\hline & Male & 10 & 33.3 & 5 & 33.3 & 5 & 33.3 \\
\hline \multirow[t]{4}{*}{ Age } & 18 to 20 years & 6 & 20.0 & 5 & 33.3 & 1 & 6.7 \\
\hline & 21 to 30 years & 10 & 33.3 & 4 & 26.7 & 6 & 40.0 \\
\hline & 31 to 40 years & 11 & 36.7 & 4 & 26.7 & 7 & 46.7 \\
\hline & 41 to 46 years & 3 & 10.0 & 2 & 13.3 & 1 & 6.7 \\
\hline \multirow[t]{3}{*}{ Age at onset of parental disorder } & 0 to 10 years & 13 & 43.3 & 7 & 46.7 & 6 & 40.0 \\
\hline & 11 to 20 years & 6 & 20.0 & 3 & 20.0 & 3 & 20.0 \\
\hline & Over 21 years & 11 & 36.7 & 5 & 33.3 & 6 & 40.0 \\
\hline \multirow[t]{2}{*}{ Marital status } & Single & 13 & 43.3 & 7 & 46.7 & 6 & 40.0 \\
\hline & Living with partner & 17 & 56.7 & 8 & 53.3 & 9 & 60.0 \\
\hline \multirow[t]{2}{*}{ Child is the patient's custodian } & Yes & 2 & 6.7 & 2 & 13.3 & - & - \\
\hline & No & 28 & 93.3 & 13 & 86.7 & 15 & 100.0 \\
\hline \multirow[t]{5}{*}{ Contact with patient (per week) } & Up to $2 \mathrm{~h}$ & 13 & 43.3 & 9 & 60.0 & 4 & 26.7 \\
\hline & 2 to $5 \mathrm{~h}$ & 9 & 30.0 & 3 & 20.0 & 6 & 40.0 \\
\hline & 5 to $15 \mathrm{~h}$ & 2 & 6.7 & - & - & 2 & 13.3 \\
\hline & 15 to $35 \mathrm{~h}$ & 5 & 16.7 & 3 & 20.0 & 2 & 13.3 \\
\hline & More than $35 \mathrm{~h}$ & 1 & 3.3 & - & - & 1 & 6.7 \\
\hline \multirow[t]{2}{*}{ Characteristics of the parent (patient) sample } & & \multicolumn{2}{|c|}{ Total $[N=30]$} & \multicolumn{2}{|c|}{ F31 $[n=15]$} & \multicolumn{2}{|c|}{$\mathrm{F} 32 / 33[n=15]$} \\
\hline & & {$[N]$} & [\%] & {$[n]$} & [\%] & {$[n]$} & [\%] \\
\hline \multirow[t]{3}{*}{ Diagnosis (ICD-10) } & F31 & 15 & 50.0 & 15 & 100.0 & - & - \\
\hline & F32 & 4 & 13.3 & - & - & 4 & 26.7 \\
\hline & F33 & 11 & 36.7 & - & - & 11 & 73.3 \\
\hline \multirow[t]{2}{*}{ Gender } & Female & 19 & 63.3 & 7 & 46.7 & 12 & 80.0 \\
\hline & Male & 11 & 36.7 & 8 & 53.3 & 3 & 20.0 \\
\hline \multirow[t]{3}{*}{ Age } & 41 to 49 years & 9 & 30.0 & 4 & 26.7 & 5 & 33.3 \\
\hline & 50 to 59 years & 10 & 33.3 & 6 & 40.0 & 4 & 26.7 \\
\hline & 60 to 69 years & 11 & 36.7 & 5 & 33.3 & 6 & 40.0 \\
\hline \multirow[t]{2}{*}{ Marital status } & Single & 5 & 16.7 & 1 & 6.7 & 4 & 26.7 \\
\hline & Living with partner & 25 & 83.3 & 14 & 93.3 & 11 & 73.3 \\
\hline \multirow[t]{4}{*}{ Number of children } & 1 & 7 & 23.3 & 5 & 33.3 & 2 & 13.3 \\
\hline & 2 & 13 & 43.3 & 7 & 46.7 & 6 & 40.0 \\
\hline & 3 & 7 & 23.3 & 3 & 20.0 & 4 & 26.7 \\
\hline & 4 & 3 & 10.0 & - & - & 3 & 20.0 \\
\hline \multirow[t]{2}{*}{ Ever attempted suicide } & Yes & 11 & 36.7 & 8 & 53.3 & 3 & 20.0 \\
\hline & No & 19 & 63.3 & 7 & 46.7 & 12 & 80.0 \\
\hline \multirow[t]{2}{*}{ Legal tutelage } & Yes & 4 & 13.3 & 4 & 26.7 & - & - \\
\hline & No & 26 & 86.7 & 11 & 73.3 & 15 & 100.0 \\
\hline
\end{tabular}


Table 1 Characteristics of the children and patient sample (Continued)

\begin{tabular}{|c|c|c|c|c|c|c|c|}
\hline \multirow{5}{*}{$\begin{array}{l}\text { CGI (clinical global impression; } \\
\text { severity of the disorder) at date of discharge }\end{array}$} & Mildly ill & 7 & 23.3 & 2 & 13.3 & 5 & 33.3 \\
\hline & Moderately ill & 6 & 20.0 & 4 & 26.7 & 2 & 13.3 \\
\hline & Considerably ill & 6 & 20.0 & 4 & 26.7 & 2 & 13.3 \\
\hline & Severely ill & 7 & 23.3 & 2 & 13.3 & 5 & 33.3 \\
\hline & No data provided & 4 & 13.3 & 3 & 20.0 & 1 & 6.7 \\
\hline
\end{tabular}

$\mathrm{OBD}=$ offspring of patients with bipolar disorder; ODD = offspring of patients with depressive.

and are in urgent need of professional support. This study found aspects of burden which are special to children in the role as caregivers of psychiatric patients. While some of the children's statements have been published in previous caregiver research (Moeller-Leimkuehler 2005; Reinares and Vieta 2004; Schmid et al. 2003; Schmid et al. 2005), our results provide new details on how children experience parental affective disorder. What is more, our study compares the perceived burden of OBD and ODD. Burdens specific to children are fear of parental illness developing in oneself and/or in one's children (statement listed in category 'emotional burden', reported by 66.7\%; see Table 2), lack of emotional support, as well as lack of harmony/divorce (statements listed in category 'burden due to impaired family life', each reported by $53.3 \%$; see Table 2). Overall, coherence between OBD and ODD is high. However, there are two significant differences, the first of which was greater dissatisfaction with the patient's therapy/professional staff in ODD. Whereas recovery from mania can be quite fast, especially under suitable medication, this does not hold true for depression which typically requires long-term therapy: the success of which is not immediately noticeable to the patient's caregivers. This might lead to dissatisfaction with professional staff. OBD reported more burden due to impaired functioning in school/job showing that burden due to parental affective disorder continues on into adulthood. A potential reason could be that OBD worry more about both the ill parent as well as about the healthy parent since bipolar disorder is a more severe illness (e.g., low predictability of episodic course, high relapse rate, illness with two poles - depression and mania) with immense impact on family life compared to unipolar depression.

\section{Reward experienced by adult children as caregivers}

Adult children of mentally ill parents experience an unexpectedly high amount of reward due to parental disorder. Many relatives are highly aware of positive aspects resulting from caring for a psychiatric family member (Hatfield 1997); children, in particular, are reported to be very sensitive to experiencing reward (Hinrichsen et al. 1992). Unlike other findings (Heru and Ryan 2004), OBD and ODD of this sample surprisingly did not differ in frequency of reported reward. Most

Table 2 Frequencies of categories and statements of burden as reported by the children sample

\begin{tabular}{|c|c|c|c|c|c|c|c|}
\hline \multirow[t]{2}{*}{ Categories and statements of reported burden } & \multicolumn{2}{|c|}{ Total $[N=30]$} & \multicolumn{2}{|c|}{$\mathrm{OBD}[n=15]$} & \multicolumn{2}{|c|}{ ODD $[n=15]$} & \multirow[t]{2}{*}{$p(a)$} \\
\hline & {$[N]$} & [\%] & {$[n]$} & [\%] & {$[n]$} & [\%] & \\
\hline Emotional burden & 30 & 100.0 & 15 & 100.0 & 15 & 100.0 & 1.0 \\
\hline - Anxiety and concern for the patient & 22 & 73.3 & 14 & 93.3 & 8 & 53.3 & $.02^{*}$ \\
\hline - Fear of illness of one's own/hereditariness & 20 & 66.7 & 10 & 66.7 & 10 & 66.7 & .65 \\
\hline - Confusion and helplessness due to the patient's behavior & 15 & 50.0 & 8 & 53.3 & 7 & 46.7 & .50 \\
\hline - Fear of what the future might bring & 15 & 50.0 & 10 & 66.7 & 5 & 33.3 & .07 \\
\hline Burden due to impaired family life & 27 & 90.0 & 15 & 100.0 & 12 & 80.0 & .11 \\
\hline - Lack of emotional support & 16 & 53.3 & 9 & 60.0 & 7 & 46.7 & .36 \\
\hline - Lack of harmony/divorce & 16 & 53.3 & 4 & 26.7 & 3 & 20.0 & .50 \\
\hline Burden due to the patient's symptoms & 23 & 76.7 & 12 & 80.0 & 11 & 73.3 & .50 \\
\hline - Patient's lack of insight into the disorder & 16 & 53.3 & 9 & 60.0 & 7 & 46.7 & .36 \\
\hline Burden due to dissatisfaction with the patient's therapy/professional staff & 22 & 73.3 & 8 & 53.3 & 14 & 93.3 & $.02^{*}$ \\
\hline - Lack of dedication of professional staff & 15 & 50.0 & 6 & 40.0 & 9 & 60.0 & .23 \\
\hline - Lack of professional support/involvement in therapy & 15 & 50.0 & 7 & 46.7 & 8 & 53.3 & .50 \\
\hline Burden due to impaired free-time activities & 19 & 63.3 & 9 & 60.0 & 10 & 66.7 & .50 \\
\hline Burden due to impaired functioning in school/job & 14 & 46.7 & 10 & 66.7 & 4 & 26.7 & $.03^{*}$ \\
\hline
\end{tabular}


positive results concern the intensification of the parentchild relationship. As adults, children of parents with psychiatric disorders are able to reflect on their childhood experiences from a more distant perspective. For most adult children of this sample, the outcome of this contemplation process seems to be not only burdensome but also a positive (learning and self-enriching) experience.

\section{Coping mechanisms of OBD and ODD}

Children of bipolar parents are more likely to use depressive ways of coping than children of depressed parents. Previous studies focusing on caregiver coping showed that relatives of depressed and bipolar patients use many different coping styles (Adewuya et al. 2011; Chakrabarti and Gill 2002). Caregivers of bipolar patients have been shown to use problem-oriented coping more often than caregivers of depressive patients (Chakrabarti and Gill 2002; Nehra et al. 2005). In these previous studies, mostly the partner, parents, and siblings of affected individuals were interviewed. In contrast, OBD in our study do not use problem-oriented coping more often than ODD. Depressive coping thus appears to be unique to children of bipolar patients compared to other relatives. This is hardly surprising considering the fact that more than half of the bipolar patients in our sample have attempted suicide (see Table 1). On the other hand, as there is no data on the clinical state of the interviewed children, one cannot know whether this depressive coping mechanism is purely a result of the parent's conditions or whether it is somewhat contaminated by the children's own clinical course. Thus, data of occupation and income level of the children argue for a healthy sample.

Even though the adult children in our study reported some positive aspects of parental psychiatric illness, they predominately experienced high levels of burden. This study therefore proves that burden does not stop in adulthood.

\section{Characteristics of children who are in urgent need of professional support}

High burden due to a caring for a family member with a psychiatric disorder leads to a higher risk for developing affective disorders in caregivers (Adewuya et al. 2011; Lawton et al. 1991). Children of parents with an affective disorder are more likely to develop psychiatric illnesses (Duffy et al. 2014; Nehra et al. 2005). In addition, caregiver burden influences the clinical outcome of patients with affective disorders (Perlick et al. 2001; 2004). As a consequence, supporting patients' minor and adult offspring is a crucial target of psychosocial interventions in affective disorders. Our results provide data to identify high-risk adult children who are highly emotionally burdened and thus in urgent need of professional support. According to the results of our regression analyses, characteristics of these high-risk children and their affected parent (i.e., patient) are as follows:
- Adult child is young (18 to 20 years old)

- Child was 10 years or younger at the onset of parental disorder

- Child has a cohabitating relationship

- Child is the patient's legal custodian

- Child reports many burdensome aspects

- Parent is diagnosed with bipolar disorder

- Parent has a severe disorder

- Parent is single

- Parent is not under legal tutelage

- Parent has attempted suicide

Opposite to results of previous studies (Mitsonis et al. 2012), duration of illness did not predict caregiver burden for children. In addition, contrary to other findings (Hadryś et al. 2011), children's burden did differ according to diagnostic group with bipolar disorder being associated to higher burden in children.

\section{Methodological considerations}

Small sample size and large age range limit the degree to which these results can be generalized. Also, the interviewed children were not evaluated clinically for presence or history of any kind of psychiatric disorders. Thus, data of occupation and income level argue for a healthy sample. Most interviewed children work full time (70.0\%) or part time (20\%); $10 \%$ were housewives. None of them receive a pension, and the income level was relatively high. Furthermore, subjects were recruited primarily from a hospital setting and included only children who were willing to participate. These findings are, thus, limited in their applicability to other populations such as children of parents with less severe or less chronic conditions.

We have increased our knowledge about the clinical importance of supporting children of mentally ill parents. Introducing psychoeducational interventions and, as a result, reducing burden and promoting problem-oriented coping will not only diminish the children's own risk of developing psychiatric disorders but also improve the clinical outcome among patients with affective disorders (Perlick et al. 2001). Therefore, reducing burden in this high-risk group of caregivers will prevent future psychiatric illnesses. Prevention programs that are proven to have long-term positive effects on children affected by parental disorder (Beardslee et al. 2003; Siegenthaler et al. 2012) should be implemented now.

\section{Conclusions}

Although some positive aspects of parental affective disorder exist, this study underlines that children primarily suffer from their parent's disorder in important areas of their life and that this burden does not stop in adulthood. Providing professional support to adult as well as to minor children of affected individuals should become standard of care in hospital settings. 


\section{Competing interests}

The authors declare that they have no competing interests.

\section{Authors' contributions}

$\mathrm{RB}$ conceived the study, did the design, helped in the statistical analysis, and drafted the manuscript. HS participated in the design of the study and its coordination and helped to draft the manuscript. $\mathrm{MH}$ coordinated the study, performed the statistical analysis, and helped to draft the manuscript. All authors read and approved the final manuscript.

\section{Author details}

${ }^{1}$ Department of Psychiatry and Psychotherapy, University Hospital Carl Gustav Carus, Technical University Dresden, Fetscherstr. 74, 01307 Dresden, Germany. ${ }^{2}$ Department of Psychiatry and Psychotherapy, University of Regensburg, Universitätsstraße 84, 93053 Regensburg, Germany. ${ }^{3}$ State Hospital for Psychiatry, Psychotherapy and Psychosomatics, Prof.-Buchner-Strasse 22, 84034 Landshut, Germany. ${ }^{4}$ Department of Psychiatry and Psychotherapy II, BKH Günzburg, Ulm University, Ludwig-Heilmeyer-Str. 2, 89312 Günzburg, Germany.

Received: 24 October 2014 Accepted: 5 January 2015 Published online: 31 January 2015

\section{References}

Adewuya AO, Owoeye OA, Erinfolami AR. Psychopathology and subjective burden amongst primary caregivers of people with mental illness in South-Western Nigeria. Soc Psychiatry Psychiatr Epidemiol. 2011;46:1251-6. doi:10.1007/s00127-010-0293-0.

Bauer M, Glenn T, Keil M, Bauer R, Marsh W, Grof P, et al. Brief depressive symptoms in patients with bipolar disorder: analysis of long-term self-reported data. Aust N Z J Psychiatry. 2012a;46:1068-78. doi:10.1177/0004867412452017.

Bauer R, Koepke F, Sterzinger L, Spiessl H. Burden, rewards, and coping - the ups and downs of caregivers of people with mental illness. J Nerv Ment Dis. 2012b;200:928-34. doi:10.1097/NMD.0b013e31827189b1.

Bauer R, Sterzinger L, Koepke F, Spiessl H. Rewards of caregiving and coping strategies of caregivers of patients with mental illness. Psychiatr Serv. 2013;64:185-8. doi:10.1176/appi.ps.001212012.

Beardslee WR, Gladstone TRG, Wright EJ, Cooper AB. A family-based approach to the prevention of depressive symptoms in children at risk: evidence of parental and child change. Pediatrics. 2003;112:119-31.

Chakrabarti S, Gill S. Coping and its correlates among caregivers of patients with bipolar disorder: a preliminary study. Bipolar Disord. 2002;4:50-60.

Chakrabarti S, Kulhara P, Verma SK. Extent and determinants of burden among families of patients with affective disorder. Acta Psychiatr Scand. 1992;86:247-52.

Cleary M, Freeman A, Hunt GE, Walter G. What patients and carers want to know: an exploration of information and resource needs in adult mental health services. Aust N Z J Psychiatry. 2005;39:507-13.

Coryell W, Scheftner W, Keller M, Endicott J, Maser J, Klerman GL. The enduring psychosocial consequences of mania and depression. Am J Psychiatry. 1993;150:720-7.

Duffy A, Horrocks J, Doucette S, Keown-Stoneman C, Grof P, Andreazza A, et al. Immunological and neurotrophic markers of risk status and illness development in high-risk youth: understanding the neurobiological underpinnings of bipolar disorder. Int J Bipolar Disorders. 2014;2:4. doi:10.1186/2194-7511-2-4.

Hadryś T, Adamowski T, Kiejna A. Mental disorder in Polish families: is diagnosis a predictor of caregiver's burden. Psychiatry Psychiatr Epidemiol. 2011;46:363-72. doi:10.1007/s00127-010-0200-8.

Hatfield A. Families of adults with severe mental illness: new directions in research. Am J Orthopsychiatry. 1997;67:254-60.

Heru AM, Ryan CE. Burden, reward and family functioning of caregivers for relatives with mood disorders: 1-year follow-up. J Affect Disord. 2004;83:221-5.

Hinrichsen GA, Hernandez NA, Pollack S. Difficulties and rewards in family care of the depressed older adult. Gerontologist. 1992;32:486-92.

Hjäthag F, Helldin L, Karilampi U, Norlander T. Illness-related components for the family burden of relatives to patients with psychotic illness. Soc Psychiatry Psychiatr Epidemiol. 2010;45:275-83. doi:10.1007/s00127-009-0065-x.ocial.

Krautgartner M, Unger A, Göessler R, Rittmannsberger H, Simhandl C, Grill W, et al. Minor relatives of schizophrenia patients: burden and needs. Neuropsychiatr. 2007;21:267-74.
Lawton MP, Moss M, Kleban MH, Glicksman A, Rovine M. A two-factor model of caregiving appraisal and psychological well-being. J Gerontol. 1991;46:181-9.

Maoz H, Goldstein T, Goldstein Bl, Axelson DA, Fan J, Hickey MB, et al. The effects of parental mood on reports of their children's psychopathology. J Am Acad Child Adolesc Psychiatry. 2014;53:1111-22. doi:10.1016/j.jaac.2014.07.005.

Mayring P. Qualitative content analysis. Basic principles and methods. Beltz Deutscher Studien Verlag: Weilheim; 2000.

Mitsonis C, Voussoura E, Dimopoulos N, Psarra V, Kararizou E, Latzouraki E, et al. Factors associated with caregiver psychological distress in chronic schizophrenia. Soc Psychiatry Psychiatr Epidemiol. 2012;47:331-7. doi:10.1007/s00127-010-0325-9.

Moeller-Leimkuehler AM. Burden of relatives and predictors of burden. Baseline results from the Munich 5-year-follow-up study on relatives of first hospitalized patients with schizophrenia or depression. Eur Arch Psychiatry Clin Neurosci. 2005;255:223-31.

Muthny FA. Freiburg questionnaire of coping with disease - Manual. Weilheim: Beltz; 1989

Nehra R, Chakrabarti S, Kulhara P, Sharma R. Caregiver-coping in bipolar disorder and schizophrenia. A re-examination. Soc Psychiatry Psychiatr Epidemiol. 2005;40:329-36.

Perlick DA, Clarkin JF, Raue P, Sirey PH. Impact of family burden and patient symptom status on clinical outcome in bipolar affective disorder. J Nerv Ment Dis. 2001;189:31-7.

Perlick DA, Rosenheck JF, Clarkin P, Maciejewski PC, Sirey J, Struenig E, et al. Impact of family burden and affective response on clinical outcome among patients with bipolar disorder. Psychiatr Serv. 2004;55:1029-35.

Reinares M, Vieta E. The burden on the family of bipolar patients. Clin Approaches Bipolar Disord. 2004;3:17-23.

Reinares M, Vieta E, Colom F, Martínez-Arán A, Torrent C, Comes M, et al. What really matters to bipolar patients' caregivers: sources of family burden. J Affect Disord. 2006;94:157.

Schmid R, Spiessl H, Cording C. Between responsibility and delimitation: emotional distress of caregivers. Psychiatr Prax. 2005;32:272-80.

Schmid R, Spiessl H, Vukovich A, Cording C. Burden of relatives and their expectations towards psychiatric institutions. A review of the literature and own results. Fortschr Neurol Psychiatr. 2003;71:118-28.

Schwartz C, Gidron R. Parents of mentally ill adult children living at home: rewards of caregiving. Health Soc Work. 2002;27:145-54.

Siegenthaler E, Munder T, Egger M. Effect of preventive interventions in mentally ill parents on the mental health of the offspring: systematic review and meta-analysis. J Am Acad Child Adolesc Psychiatry. 2012;51:8-17. doi:10.1016/ j.jaac.2011.10.018.

Silverman DJ. Interpreting qualitative data. Methods for analysing talk text and interaction. London: Sage Publications; 2001.

Stelling K, Habers I, Jungbauer J. Between taking responsibility and becoming independent. Adolescents with a mentally ill parent. Prax Kinderpsychol Kinderpsychiatr. 2008;57:757-73.

Veltman A, Cameron J, Stewart DE. The experience of providing care to relatives with chronic mental illness. J Nerv Ment Dis. 2002;190:108-14. PMID: 11889365.

\section{Submit your manuscript to a SpringerOpen ${ }^{\circ}$ journal and benefit from:}

- Convenient online submission

- Rigorous peer review

- Immediate publication on acceptance

- Open access: articles freely available online

- High visibility within the field

- Retaining the copyright to your article

Submit your next manuscript at $>$ springeropen.com 